\title{
Current and Potential Use of Citrus Essential Oils
}

\author{
Eristanna Palazzolo, Vito Armando Laudicina* and Maria Antonietta Germanà
}

Dipartimento Scienze Agrarie e Forestali, Università degli Studi di Palermo, Viale delle Scienze, Edificio 4, 90128 Palermo, Italy

\begin{abstract}
Since the Middle Ages, citrus essential oils (EOs) have been widely used for their bactericidal, virucidal, fungicidal, antiparasitical, insecticidal, medicinal and cosmetic proprieties. Also nowadays, they find important applications in pharmaceutical, sanitary, cosmetic, agricultural and food industries. The best method to extract EOs from citrus plant tissue is steam distillation because of a variety of extracted volatile molecules such as terpenes and terpenoids, phenol-derived aromatic components and aliphatic components. In vitro physicochemical assays classify most of them as antioxidants.
\end{abstract}

Keywords: Peel oils, Neroli oils, Petitgrain, Application of EOs, Taxonomical markers, Antimicrobial activity.

\section{INTRODUCTION}

Plants provide many advantages (ornament, oxygen, food, beverages, clothing, perfumes and building materials) and moreover, they are source of an enormous number of compounds, known as 'secondary metabolites'. The latter play a major defensive and attractive role in the interactions between plants and their environment (with other plants, herbivores, pathogens and pollinators). As reported by Figueiredo et al. [1], secondary metabolites (a) have no direct implication on the growth and development of plants, (b) are often synthesized from primary metabolites, (c) have a distribution which is sometimes confined to a genus or species, (d) are often accumulated in high concentrations (1-3\% fresh weight), (e) may show high toxicity, (f) may have a marked biological effect on other organisms, (g) frequently have different production and accumulation sites and (h) are sometimes accumulated in the vacuoles in a glycosidic form or accumulate in special secretory structures, e.g. trichomes, ducts, canals, laticifers.

Essential oils (EOs, also called volatile or ethereal oils [2]) are aromatic oily liquids characterized by a strong odour and produced by different plant material (flowers, buds, seeds, leaves, twigs, bark, herbs, wood, fruits and roots) as secondary metabolites. EOs are liquid, volatile, limpid and rarely coloured, soluble in organic solvents generally with a lower density than water. They are very complex natural mixtures of lipophilic substances, which can contain about 20-60 components at different concentrations. They are characterized by two or three major components (limonene, pcymene and ocimene) at fairly high concentrations (20-70\%) compared to others components present in trace amounts. Generally, those major components determine the biological properties of the EOs [3]. At present, approximately 3000 EOs are known, 300 of which are commercially important and used for pharmaceutical, agronomic, food, sanitary, cosmetic and perfume industries purposes.

Since the Middle Ages, Arabs have extracted EOs by steam or hydro-distillation from various aromatic plants. Nowadays other methods, such as water, steam, organic solvent extraction, cold pressing, as well as, supercritical $\mathrm{CO}_{2}$, have been used to extract

*Address correspondence to this author at the Dipartimento Scienze Agrarie e Forestali, Università degli Studi di Palermo, Viale delle Scienze, Edificio 4, 90128 Palermo, Italy; Tel: +39 091 23897074; Fax: +39091 484035;

E-mail: vitoarmando.laudicina@unipa.it
EOs from plants. Supercritical $\mathrm{CO}_{2}$ extraction is a technique by which EOs are extracted at lower temperature to avoid potential damage to desired compounds at high temperatures. Such a technique has been demonstrated to be an effective method to extract EOs from citrus fruit peels [4-7]. The method used to extract EOs greatly affects their chemical profile (number and stereo chemistry of extracted molecules). Hence the choice of extraction method depends also on the purpose of the use. Besides extraction procedure, EOs can vary in quality, quantity and composition according to climate, soil type, plant organ, age and vegetative cycle stage of plant $[8,9]$. So, in order to obtain EOs with a constant composition, all those factors of variability have to be taken into account.

In nature, EOs play an important role in the protection of the plants as antibacterials, antivirals, antifungals, insecticides and also against herbivores by reducing their appetite for such plants. They may also attract some insects to favour the dispersion of pollens and seeds, or repel undesirable others. Due to their bactericidal and fungicidal properties, they are also used as alternatives to synthetic chemical products to protect the ecological equilibrium without showing the same secondary effects [10]. Known for their antiseptic and medicinal properties and for their fragrance, they are used in embalmment, preservation of foods and as antimicrobial, analgesic, sedative, anti-inflammatory, spasmolytic and locally anaesthetic remedies. In those cases, extraction by steam distillation is preferred. On the contrast, for perfume uses, extraction with lipophilic solvents or with supercritical carbon dioxide is favoured. Most of the commercialized EOs are chemotyped by gas chromatography and mass spectrometry analysis. Analytical monographs have been published (European pharmacopoeia, ISO, WHO, Council of Europe; [11]) to ensure good quality of treated EOs.

Nowadays, thanks to the research activity on the characteristics of EOs, more is known about some of their action mechanisms, particularly at the antimicrobial level. The antimicrobial properties of EOs have been recognised for centuries and, with growing demand from changes in legislation, consumer trends and increasing isolation of antibiotic resistant pathogens, alternatives to chemical based bactericides need to be found. Low molecular weight compounds of EOs allow them to easily penetrate through cell walls and affect various biochemical processes [3]. The biological activity of EOs depends on their composition. The major components of EOs with antibacterial properties are geranyl acetate, eugenyl acetate, menthol, carvacrol, thymol, geraniol, eugenol, p-cymene, limonene, 
$\gamma$-terpinene, carvone. The phenolic components are chiefly responsible for the antibacterial properties of EOs [12]. An important characteristic of EOs seems to be their composition stability, although little is known about changes in composition during the storage.

EOs are also used for massages as mixtures with vegetal oil or in baths. In addition, EOs have a strong psycho-emotional effect thanks to they are used for aromatherapy. Some EOs appear to exhibit particular medicinal properties that have been claimed to cure organ dysfunction or systemic disorder [13-15].

Due to the new attraction for natural products like EOs, despite their wide use and being familiar to us as fragrances, it is important to develop a better understanding of their mode of biological action for new applications in human health, agriculture and environment.

Citrus species (Rutaceae), native of the tropical regions of South-east Asia and China, nowadays represent the largest fruit production worldwide, with over 123 million of tons produced during 2010 [16]. More than 100 countries, between approximately $40^{\circ}$ $\mathrm{N}$ and $40^{\circ} \mathrm{S}$ around the world, cultivate citrus plants. The most important producing countries are China, Brazil, United States and regions of the Mediterranean Basin.

The most commercially important citrus species are sweet oranges (Citrus sinensis L. Osbeck) and tangerines (Citrus unshiu Marc., Citrus nobilis Lour., Citrus deliciosa Ten., Citrus reticulata Blanco and their hybrids) (more than $80 \%$ ), followed by lemons (Citrus limon L. Burm. f.), limes (Citrus aurantifolia Christm. Swing.) and grapefruits (Citrus paradisi Macf.). The genus Citrus is related to other genera of the family Rutaceae, such as Fortunella, Poncirus, Microcitrus, Clymenia, and Eremocitrus.

Citrus have a strong commercial value. They are produced mainly for the fresh consumption, but they are also addressed to the food industry for the production of fruit juice. Moreover, the byproducts generated following their industrial process are source of important bioactive compounds with potential for animal feed, manufactured foods and health care [17]. Among the citrus byproducts, EOs have been produced for more than a thousand years. The main producing countries are Italy (particularly Sicily), USA (Florida) and South America (Brazil, Argentina). The fruit of citrus is a hesperidium, a type of berry with a pericarp (divided in exocarp or flavedo, mesocarp or albedo and endocarp) and segment, filled with juice sacs (vesicles), actually specialized hair cells [18] (Fig. 1).

Approximately $50 \%$ of the citrus fruit weight consists of pulp, seeds and peel, which can be processed into value-added byproducts such as molasses, pectins, fiber, seed oils, fermentation products and EOs [19].

In all citrus species of the Rutaceae family, essence of oil secretory cavities (glands) have been reported.

Oil glands are spherical structures just under the epidermis in primary tissues of the shoot (i.e. leaf, thorns, prophyllis, sepals, etc.) [18] and, particularly, in flavedo. The latter is the pigmented region of the pericarp, contains numerous oil glands (Fig. 2) consisting of secretory cavities that are lined by several layers of specialized epithelial cells. Recently, Yamasaki and Akimitsu [20] have hypothesized that the epithelial cells are responsible for the biosynthesis of EOs.

A research carried out by Germanà et al. [21] on the distribution of oil glands in the lemon fruits of 44 different clones, showed as the stilar part of the fruit is characterized by the highest density

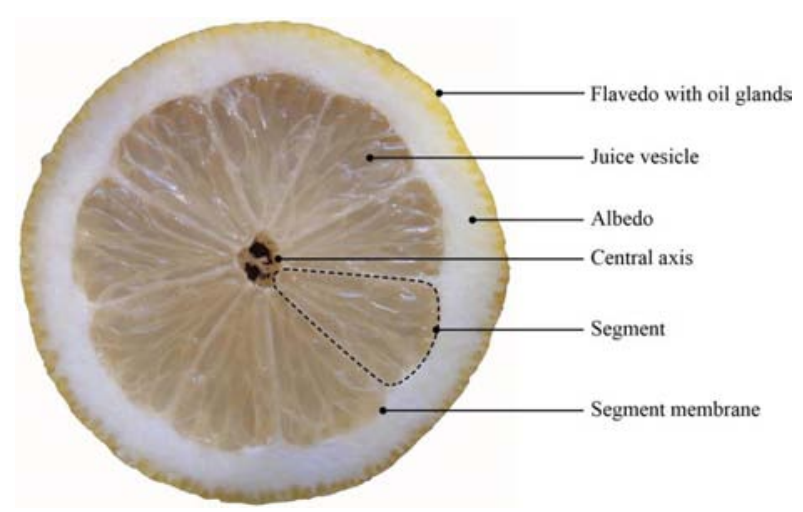

Fig. (1). Cross section of lemon fruit.

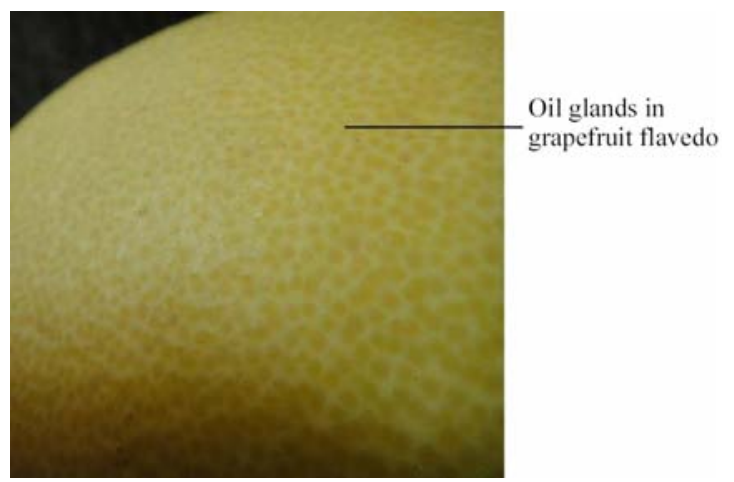

Fig. (2). Oil glands in grapefruit flavedo.

of oil glands. Another study [22] on three cultivars (Femminello, Castagnaro and Fantastico) bergamot (Citrus bergamia Risso) confirmed the influence of the genotype also at cultivar level on the density of the oil glands. The results showed as Femminello and Fantastico cultivars presented the highest number of glands per unit area in the peel, as well as in the leaves. Nevertheless, no relationship was observed between oil glands density and oil yield. Besides in leaves and in fruit peel, oil glands are present also in flowers (sepals, petals and ovary wall; Fig. 3). Oil glands in sepals, petals and ovary wall appeared at different time intervals, but showed the same histological aspect. In fruits, oil gland appearance was restricted to the immature stage. No new gland was formed during the fruit maturation process and the preformed ones continued to enlarge. The developmental pattern of secretory glands of the flower and fruit peel is separated into four stages, based on cell features and the degree of gland differentiation. Oil glands in Citrus are of schizolysigenous type [23].

The present chapter deals with the actual and potential applications of citrus EOs in the different fields of human life and activity.

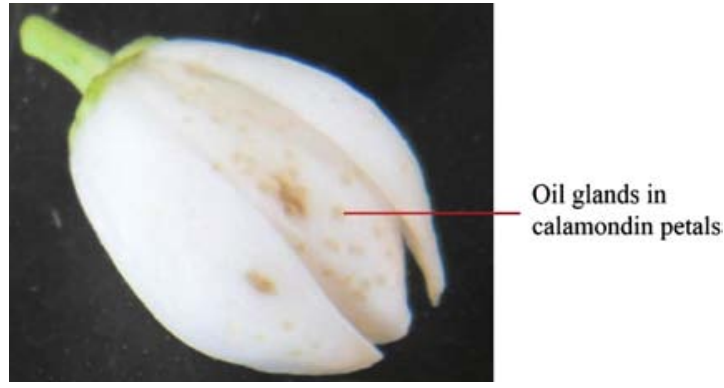

Fig. (3). Oil glands in calamondin petals. 


\section{THE CITRUS ESSENTIAL OILS}

The citrus EOs are present and can to be extracted from peels, flowers and from young citrus shoot, buds and leaves.

\subsection{Peel Oil}

The quality and quantity of citrus peel EOs depend on many factors, such as the nature of the fruit itself, provenance, genotype, soil type and climate but also on the extraction process [24]. The oil content of citrus peels range between 0.5 and $5.0 \%(\mathrm{w} / \mathrm{v})$.

EOs extracted from citrus peel are very complex matrices containing numerous compounds of different chemical classes. These compounds are generally divided in two fractions: the volatile fraction, which is the most representative and ranges between 85 and $99 \%$ in the different cold-pressed citrus oils, and the non-volatile residue, containing fatty acids, sterols, carotenoids, waxes, coumarins, and polymethoxylated flavonoids (2-6\% of the oil), which ranges between 1 and $15 \%$ [24]. The volatile constituents are a mixture of monoterpene (limonene) and sesquiterpene hydrocarbons and their oxygenated derivatives including aldehydes (citral), ketones, acids, alcohols (linalool) and esters [25-27].

The development of new instrumental analytical techniques, mainly chromatographic, has allowed a more precise characterization of EOs citrus. Gas chromatography is an essential tool for the study of the volatile fraction, while liquid chromatography (thinlayer or high-performance liquid chromatography combined with spectral absorption and fluorescence measurements) is widely used for the study of the composition of the non-volatile residue. This fraction consists largely of oxygen heterocyclic compounds (coumarins, furanocoumarins and polymethoxylated exhibit strong absorption in the ultraviolet region $(\max 315 \mathrm{~nm})$ ). The presence of coumarin compounds is widespread in plants of the Rutaceae family. Their presence is qualitatively and quantitatively different in the various citrus oils, so it could be of particular interest the knowledge of the oxygen heterocyclic fraction to assess authenticity, geographical origin and possible adulteration of EOs [24]. The major chemical component of citrus oils is limonene. The limonene content ranges from 32 to $98 \%$. In particularly, the limonene content ranges from 68 to $98 \%$ in sweet orange, from 45 to $76 \%$ in lemon and from 32 to $45 \%$ in bergamot [28]. About linalool, an oxygenated component, its concentration results $0.018,0.015$ and $10.231 \%$ in sweet orange, lemon and bergamot, respectively [29].

The influence of the harvesting period (seven different times: 4 winter lemons, 2 bianchetti, 1 verdelli) on the yield of EOs from the peel of four lemon (C. limon (L.) Burm. f.) cultivars (two Femminello, Monachello and Eureka) has been investigated [30]. Regarding the yield in EOs, verdelli registered the highest values, with decreasing yield from November to February in the 4 winter samples considered, increasing yield in bianchetti. Referring to the genotypes, the 2 Femminello showed the greatest yield in EOs, followed by Monachello and Eureka, with similar values. The greatest limonene content was registered in the first winter samples and, regarding the genotype, in the cultivar Monachello, while the Femminello 7 was characterized by the highest citral (mixture of geranial and neral) content and the lowest limonene content.

\subsection{Neroli Oil}

Neroli oil is obtained from flowers of bitter orange (Citrus aurantium L.), although this term is also referred to oils extracted from other citrus flowers. The term 'Neroli' is due to the princess
Anna Maria de la Tremoille de Noirmutier, wife of Flavio Orsini prince of Nerola, who liked the orange flower water.

The yield and sensory characters of Neroli oils are related to numerous factors, such as the raw material conditions at harvest time, the type of transport and storage conditions and the extraction procedure. The main component extracted from the EOs of orange blossom is linalool with a concentration of $40 \%(w / v)$ [31]. The aldehydes were found in lemon, orange and bergamot essential flower oils, for the most part in the form of neral and geranial stereoisomers [32].

There are numerous varieties of bitter orange. A study of Crescimanno et al. [33], carried out on Neroli oils extracted from 15 different $C$. aurantium clones by distillation, showed that EOs yield ranged from 0.74 to $1.02 \mathrm{~mL} \mathrm{~kg}^{-1}$ of flowers with values similar to those reported by Pennisi [34] for bitter orange flowers and lower than those reported by Melendreras et al. [35] for lemon flowers. Quantitative rather than qualitative differences were present among the genotypes. Particularly, all clones were characterized by the same number of components, both hydrocarbons and oxygenated compounds (except the A.A. clone C.N.R. 8 where $\alpha$-pinene was not found). Terpenes, sesquirepenes, alcohols and acetates were found in Neroli oils. The terpene compounds more represented were limonene (from $0.72 \%$ to $15.32 \%$ of the total identified components) and $\beta$-pinene (about 5\%). These values resulted much lower than those found by Melendreras et al. [35] in Neroli oils of lemon. Among oxygenated compounds, linalool made up $63 \%$ of the identified compounds (about $80 \%$ of the total ones), followed by the citral (neral and geranial) (about 7.97\%). Differences among the genotypes regarding the levels of oxygenate compounds and hydrocarbons were registered. Linalool naturally occurs in the fragrance of flowering plants, particularly in many citrus genotypes [36]. Linalool is an acyclic monoterpene alcohol (3,7-dimethyl-1,6octadien-3-ol) with a sweet, pleasant fragrance widely occurring among diverse monocot and dicot families and is one of the most frequently encountered floral scent compounds. Linalool is prized by the flavour and fragrance industry as a component of bergamot and lavender EOs and numerous commercial perfumes.

An investigation has been carried out on the EOs extracted from the flowers and from the different parts (petals, pistils, stamens) of the main bergamot cultivars: Femminello, Castagnaro and Fantastico, showing the highest $(4.14 \%)$ yield in the Fantastico cultivar (in the entire flower as well as in the single parts), followed by Castagnaro and Femminello [37]. Moreover, the bergamot flowers showed a greatest EOs yield than the flowers of other genotypes (mandarin $2.59 \%$, grapefruit $2.22 \%, 1.79 \%$ lemon, $1.77 \%$ sweet orange, $1.04 \%$ sour orange) [38]. Regarding the parts of the flower, pistils in all the cultivars showed the highest EOs yield (4.24-6.84\%), followed by petals and stamens and differently from what previously observed by Germanà et al. [39] in C. aurantium, where petals presented a yield higher or at least equal to pistils.

\subsection{Petitgrain}

The term 'petitgrain' was first used to indicate the green small fruits of bitter orange, and used to name the oil obtained from them. Later this term indicated the EOs obtained by distillation from the young citrus shoot, buds and leaves.

Bitter orange petitgrain oil showed a high content of oxygenated compounds which varied from $91 \%$ to $96 \%$. Linalyl acetate, which represented more than $50 \%$ of the whole oil, and linalool, which ranged from $22 \%$ to $33 \%$, are the main components. Limonene, (E)- $\beta$-ocimene, myrcene and $\beta$-pinene are the highest 
monoterpene hydrocarbons. Also twelve sesquiterpene hydrocarbons have been identified, among which $\beta$-Caryophyllene is the most representative. Among the oxygenated compounds identified, aldehydes have been found in highest proportions. 1,8-Cineole, which is either absent or present only as trace in the other citrus petitgrains, represented $1.1-2.1 \%$ of lemon petitgrain oil. The latter is more similar to lemon peel oil, than the other citrus petitgrain oils to the correspondent peel oils.

A study [40] has been carried out on annual variation of EOs in the leaves (collected on November, February, June and September) of four lemon (C. limon (L.) Burm.f.) cultivars, showing that for the two cultivars of Femminello and for the cultivar Monachello, the highest oil yields was registered in leaves sampled in February, followed by those sampled in November, June and September. Instead, the cultivar Eureka produced the highest essential oil percentage in leaves sampled in November, followed by those ones collected February, June and September. Moreover, quantitative differences were registered depending on the harvesting periods. Particularly the greatest citral content was registered in the winter samples, followed by the spring ones. Differences regarding the citral content were observed among the cultivars and Eureka showed the highest content $(5.61 \%)$.

\section{APPLICATIONS OF CITRUS ESSENTIAL OILS}

\subsection{Food}

EOs are used for flavouring in food and are accepted by the Food and Drug Administrations as additives in certain type of foods. Citrus oils are used for food and beverages and they are Generally Recognized as Safe (GRAS), being a good starting point for the use of EOs as antimicrobials within the food industry.

Recently, a study was carried out to evaluate the inhibitory potential of EOs extracted from the fruit peel of several citrus varieties cultivated in Sicily against the most common foodborne pathogen bacteria [41]. Particularly, the antagonistic activity of the EOs extracted by hydrodistillation from the fruit peel of different cultivars of pomelo, grapefruit, orange, kumquat, mandarin and lemon, was evaluated against 43 strains of Listeria monocytogenes, 35 strains of Staphylococcus aureus and 14 strains of Salmonella enterica). Moreover, five commercial EOs were used for comparison. Most of the EOs were more effective against the Gram-positive bacteria rather than Salmonella. EOs of lemon genotypes 14 and 15 showed the best results in terms of number of strains inhibited and width of the inhibition zone. The most susceptible strain of each species $(L$. monocytogenes 133, S. aureus 473 and Salmonella Newport 50404) was used as indicator for the evaluation of the minimum inhibition concentration (MIC) of the EOs 14 and 15. The last two EOs, EO 16 (showing the weakest inhibition power among lemon EOs), and the commercial EO L (lemon) were analysed for their chemical composition. A total of 30 major compounds were identified by gas chromatography/mass spectrometry (GC/MS) and the oxygenated monoterpenes were suggested to be implicated in the process of bacterial inhibition by citrus EOs.

The antimicrobial properties, due to the phenolic compounds recognized as bioactive components with antimicrobial activity [42], combined with the aromas and flavours of EOs, led to research into their uses as potential food preservatives. The ability of citrus oils to delay spoilage and add organoleptic qualities in food products may be interesting from a commercial point of view [43, 44]. However, because of the interactions (synergisms and antagonism) between EOs and food ingredients or additives, studies aimed to maximise the antibacterial activity of EOs and to minimise the concentrations required to achieve a particular antibacterial effect are needed. In addition, the stability of EOs during food processing should be also investigated [45].

The use of citrus oils as antimicrobials in food might affect organoleptic properties of the foodstuff, so that finding an oil/component/vapour that has the greatest effect at the lowest concentration is essential. Citral is thought to be a potent characterimpact compound and a key component in lemon oil, although linalool is the overall aroma compound in orange [46].

Oxygenated compounds have better organoleptic properties, it may be beneficial to remove the terpene content [47].

Moreover, EOs could be used as an alternative to spices and herbs as they have many of the same principal flavourings, but without the potential to be carriers of bacterial and fungal spores and, in their case, there probably would be no loss of organoleptic properties.

Dias et al. [48] also used EOs for developing a low-density polyethylene flavouring films imbued with and/or lemon aroma. They showed that the films had a lower elongation due to the incorporation of active agents, combined whit a reduction of tensile strength over time. In addition, the combined use of EOs and aroma did not affect the water vapour permeability value, but regarding colour, flavouring films had a more yellow colour and were opaque. However, application of EOs in food packaging industry of biscuits was greatly appreciated by consumers.

Besides being used as a fragrance, citrus EOs have been reported to possess antibacterial activities against Escherichia coli (E. coli O157:H7) Salmonella typhimurium, L. monocytogenes and Vibrio vulnificus and to S. typhimurium on fish cubes [49].

According to the Food and Drug Administration of United States and Europe to prevent the occurrence of foodborne illnesses, it is necessary to avoid cross-contamination which mostly occurs on the surfaces of kitchen utensils. In fact, pathogenic bacteria can be transferred between raw materials, cloth, hands, and food contact surfaces to create cross-contamination. Washing with detergent at elevated temperatures is usually the most common practice to eliminate bacteria on the food contact surfaces. Unfortunately, it was reported that $S$. typhimurium, S. enteritidis, $C$. jejuni and E. coli can survive after regular washing processes [50]. Moreover, bacteria can survive on the surfaces of cutting boards and stainless steel after washing with detergent. In addition, most commercial detergents and sanitizers are artificially synthetic compounds with a negative impact on the environment and not more accepted by modern and careful to ecosystem consumers [51, 52]. Effective and natural sanitizer compounds, such as Citrus EOs, easily produced from agricultural waste, could be eco-friendly substitute to preserve the food contact form cross-contamination. In fact, EOs of lemon, orange, and bergamot were also demonstrated to possess bactericidal effect against Campylobacter jejuni, E. coli O157:H7, L. monocytogenes, Bacillus cereus, S. aureus and Acrobacter butzlei [53] in media and on foods. In addition, antifungal activities against Penicillium digitatum, Penicillium italicum [54] have been reported.

A study carried out by Lin et al. [55] have demonstrated the antibacterial efficacy of EOs extracted from peels of sweet orange fruits against Vibrio parahaemolyticus, S. typhimurium, E. coli, and $S$. aureus inoculated on the surfaces of samples of stainless steel and plastic cutting board pieces. 
However, the addition of citrus EOs to foods could affect its organoleptic characteristics [53], by altering the natural taste and/or odour. For this reasons, it is necessary to find the lower effective concentration with less effect on sensory attributes or to test if the vapour-phase generated by the EOs can be effective against foodborne pathogens and spoilage microroganisms at lower concentrations than when applied in liquid phase [56]. Caccioni et al. [54] reported the capacity of volatile compounds of orange and lemon peel to inhibit Penicillium spp.. Recently, Velàzquez-Nuñez et al. [42] investigated the antifungal efficacy of EOs extracted from peel of sweet orange (cv. Valencia) by vapour distillation, either by vapour exposure or direct addition on the growth of Aspergillus flavus. The results showed that the effect of direct addition of EOs was faster, although EOs vapours were more effective since lower concentrations were required to achieve the same antifungal effect.

\subsection{Medicine}

Current chemical, medical and pharmacological literature suggest that EOs can be successfully used in many aspect of health care. Several studies indicated that EOs have antitumor effects and that monoterpenes possess a chemopreventive action against rodent mammary, skin, liver, lung and forestomach cancers [57].

Particularly, citrus EOs seems to contain different terpens with antitumor effects. Additionally, among substances found in nature, terpenes constitute the main chemical class compound with antiulcerogenic activity [58].

Among the citrus species, C. aurantium L. is one of the most frequently used for medicinal purposes. Fruit peel, flowers and leaves are often utilized by the population for medicinal purposes. Bitter orange is widely used to treat rheumatism and tachycardia for its diuretic action [59], and also gastritis and gastric disorders [60]. The latter authors investigated the effects of EOs and of its majority constituent limonene extracted from $C$. aurantium on the gastric mucosa of animals challenged with different ulcerogenic agents that commonly attack the gastric mucosa in human. They concluded that EOs and limonene exert antiulcerogenic and gastroprotective actions. Those effects are directly related to an increase in the gastric production of mucus rooted in the modulating action that these compounds exert on prostaglandin E2 levels. Hence, those results suggest that EOs and limonene extracted from $C$. aurantium constitute an interesting adjuvant to non-steroidal anti-inflammatory drugs in the treatment of chronic inflammatory illnesses, with the prospect of annulling the aggressive gastric effect of these drugs on gastric mucosa without promoting alterations in physiological functions of the stomach [60].

Further tests carried out on animals have proven the effectiveness of limonene against some types of cancer including gastric, mammary, pulmonary adenoma and liver. Limonene has been also shown to be effective in relieving gastroesophageal reflux disorder and occasional heartburn but the action mechanism has not been elucidated [61].

For instance, a study have determined the cytotoxic effect of $C$. aurantium EOs peels against colorectal cancer, cell line (Lim1863), suggesting a potential antitumor effect treatments of colorectal cancer and other cancers [62].

The EOs extracted from citrus lemon (lemon essential oil) was found to induce various behavioural responses in both humans and animals. In humans it was found to have antidepressant effects [63] and, in addition, able to improve creativity, mood and perceived health [64-65], although the mechanism is not known. In rats, lemon essential oil was found to decrease the stress-induced behavioural acting on the sleep disorder [66].

Recently, bergamot oil was shown to be a potent antifungal agent. Sanguinetti [67], investigating the activities of bergamot natural essence on dermatophytes such as Trichophyton, $\mathrm{Mi}$ crosporum and Epidermophyton species, has demonstrated its efficacy and suggested its potential use for topical treatment of dermatophytoses.

Also Neroli oil can be engaged effectively for managing bacterial and fungal infections, especially digestive and respiratory [24].

\subsection{Cosmetics and Perfumes}

Mixtures of volatiles and EOs isolated from plants represent the 'essence' or odoriferous constituents of the plants. They have been used since early days because of pharmaceutical properties and also as flavouring agents in the manufacture of perfumes and cosmetics.

Maruzzella and co-workers [68-73] extensively studied the potential of EOs as antimicrobial agents in perfumes and cosmetics or against wood pathogens.

Cold-pressed citrus oils are known to produce phototoxic reactions as they contain photoactive furocoumarins (psoralens), a family of natural plant constituents with a coumarin basic structure attached to a furan ring [74]. They include the well-known and most potent phototoxicant bergapten [75] and other derivatives as bergamottin, citropten, herniarin or oxypeucedanin [76]. In 2001, the Scientific Committee on Cosmetic Products laid down a restriction on furocoumarin-like substances, which may be used in cosmetic products, providing that the total concentration of these substances in the finished product does not exceed one part per million $[77,78]$.

The citrus oils can be also practically used as tyrosinase inhibitors. In the human brain, tyrosinase plays an important role in neuromelanin formation, which could be central to dopamine eurotoxicity as well as contribute to the neurodegeneration associated with Parkinson's disease [79]. Ultraviolet light and environmental toxins cause reactive oxygen species such as various radicals. These radicals play important roles in the activation of tyrosinase in human skin. It has been reported that some citrus EOs exhibited radicals scavenging activity [80]. For example, Eureka lemon essential oil with a strong tyrosinase inhibitory activity has DPPH radical scavenging activity. It was reported that the radical scavenging components in Eureka lemon oil were geraniol, terpinolene, and $\gamma$ terpinene. These components were different from the tyrosinase inhibitory components, citral and myrcene. Thus, it is suggested that citrus EOs, consisting of hundreds of kinds of compounds, could inhibit melanogenesis by various actions and activities. Citral and myrcene have characteristic aromas in citrus oils. Thus, it is expected that citrus EOs could be used as skin-whitening materials with citrus like aromas in confectioneries, soap, perfumery, and cosmetology [81].

\subsection{Detergent}

Citrus EOs are processed into various formulations for industrial cleaning applications and as sustainable alternatives to traditional solvents [82].

\subsection{Aromatherapy}

It is well known that there is an effect on the brain of the aromas of EOs, administered via inhalation, resulting in behavioural changes in animals and humans [83]. Aromatherapy, a branch of 
herbology, is the therapeutic use of fragrances or at least mere volatiles to cure, mitigate or prevent diseases, infections and indispositions by means of inhalation $[84,85]$.

At the moment, it is one of the fastest growing therapies worldwide. It is reported that aromatherapy gives a feeling uplifted, stimulated, invigorated, or rejuvenated, depending on the oil used. When inhaled, the various aromas penetrate the bloodstream via the lungs causing physiologic changes. In turn, the limbic system, which controls our emotions and memories, is affected [86]. This ancient therapy has been validated as medicinal by several studies.

For instance, the traditional use as anxiolytic of C.aurantium $\mathrm{L}$. EOs was demonstrated in mice [87, 88]. Moreover, the sweet orange aroma have been reported to be anxiolytic-like for Wistar rats [89]. (+)-limonene can be used as an antianxiety agent in aromatherapy as demonstrated by an additional study carried out by Lima et al. [90], showing that (+)-limonene administered by inhalation exerted anxiolytic-like effects in the elevated plus maze test, with a pharmacological potency stronger than essential oil of $C$. aurantium and that this effect was not related to benzodiazepine receptors.

Also Neroli oil, when used in clinical aromatherapy in a nebuliser or one of the other administration techniques designed for internal absorption, is essentially a relaxant remedy. The oil targets mainly the nervous system and thereby the cardiovascular and digestive systems, reducing hyper functioning in these systems. Applications include general nervous hyper functioning involving stress-related conditions in general, as seen in conditions of anxiety, restless behaviour, fear, etc.; and smooth muscle spasms, including the heart muscle itself, such as tachycardia, vascular and cardiac spasms, colic, IBS, stress-caused diarrhea and such like. Neroli's relaxant effect is balanced by a restorative effect on the brain and a stimulant action on the organs of upper digestion. This is why the oil should be considered for blends addressing such conditions as chronic fatigue and chronic depression on one hand, and forms of indigestion arising from biliary/gastric/pancreatic deficiency on the other [24].

\subsection{Pathogen Inhibition}

Citrus EOs not only are used in food industry but also are generally recognised as safe and have been found to be inhibitory both in direct oil and vapour form against a range of both Gram-positive and Gram-negative bacteria. This group of oils may provide the natural antimicrobials that the food industry requires to fulfil both its requirements and those of the consumer [53]. The composition of the blend of components in specific ratios determines the flavour and also the possible antimicrobial effects of citrus oils (unique to each species or hybrid).

Findings showed a positive correlation between monoterpenes other limonene and sesquiterpene content of the oils and the pathogen fungi inhibition.

A research carried out by Vasudeva and Sharma [91] showed the antifungal activity against ten food borne fungal strains and ten bacterial strains of EOs isolated by hydro-distillation from the peel of fully matured ripen fruits of Citrus limettioides Tan. The authors concluded that EOs of $C$. limettioides can be used in skincare formulations for acne control, in treatment of various infectious diseases like typhoid fever, food poisoning, inflammation, sepsis, endocarditis, bladder, prostate and epididymal infections.

Gram-positive organisms are generally more sensitive to EOs than Gram-negative organisms. Undesirable organoleptic effects can be limited by careful selection of EOs according to the type of food. Synergism and antagonism between components of EOs and food constituents require more study before these substances can reliably be used in commercial applications.

\subsection{Insect Control}

A study was carried out to evaluate the toxicity of pinenes (enantiomers of alpha- and beta-) and EOs from fruit peel of orange (C. sinensis L.), lemon (C. limon L.), and bitter orange (C. aurantium $\mathrm{L}$.), containing high proportion of limonene and lower quantities of p-menthane molecules and pinenes, against the mosquito larvae of Culex pipiens (Diptera: Culicidae). EOs were isolated by hydrodistillation [92]. A strong toxicity was exhibited by the citrus EOs against larvae with the $\mathrm{LC}(50)$ values ranging from 30.1 (lemon) to $51.5 \mathrm{mg} / \mathrm{L}$ (orange) depending on the genotype and on the oil composition.

Furthermore, a research carried out by Kumar et al. [93] indicated, using contact toxicity and fumigation bioassays, the insecticidal the insecticidal activity of the EOs of sweet orange $C$. sinensis (L.) Osbeck against the larvae and pupae of housefly. In fact, significant mortality of housefly larvae and inhibition of pupae was observed in different bioassays, although fumigation showed comparatively better activity than contact, probably in relation to the significant increase in D-limonene content in vapour phase of the oil.

The licicidal and niticidal activities of some Moroccan EOs and their main components or plant oil chemotypes on Pediculus humanus capitis (head lice), were investigated through two methods: microatmosphere and direct application [86]. It was found that some oils tested were most active on lice using the micro atmosphere technique. Particularly, oils extracted from $C$. limon and $C$. sinensis (Rutaceae), Pinus pinea (Pinaceae), Myrtus communis (Myrtaceae), Cinnamomum zeylanicum (Lauraceae), Pelargonium setaceum and Chrysanthemum viscidehirtum (Compositae) acted more potently using the micro atmosphere technique $(0 \%$ of nits hatched) than in direct application (10-30\% of nits hatched).

Oil obtained from leaves of $C$. aurantium var. amara Link ( $R u$ taceae) has been tested regarding the molluscicidal activity [86] achieving a good action against Bulinus truncatus snails at tested concentrations. Whereas, oil of the fruit of the same plant exhibited potent molluscicidal activity at lower concentration $($ LC50 $=1.36$ $1.56 \mathrm{ppm})$.

\subsection{Taxonomical Contribution of EOs}

Together with analysis of DNA molecular markers and with morphological characteristics, chemical variability of secondary compounds and particularly of EOs can contribute to clarify the plant taxonomy in several taxa $[94,95]$.

Recently in Citrus, a study has been carried out to differentiate taxa at intraspecific level using rind oils of nine cultivars of mandarin originated by recent mutation (Loretina, Marisol, Arrufatina, Clemenules, Clemenpons, Hernandina, Oronules, Satsuma Okitsu, Satsuma, Owari) belonging to the C.reticulata Blanco species and 2 hybrids Fortune (C. tangerine Hort. ex Tan. x C. clementina Hort. ex Tan.) and Nova (Tangelo Orlando x C. clementina Hort. ex Tan.), obtained from ripe fruits of trees growing in the same environmental and cultivated conditions [98]. The Authors showed the usefulness of phytochemical compounds to discriminate the genotypes.

In fact, the levels of $\alpha$-thujene, $\alpha$-pinene and sabinene compounds could be used to differentiate among cultivars and particularly, the first discriminant function separates the $\alpha$-thujene 
chemocultivar, corresponding to oriental mandarin cultivars (Satsuma Okitsu, Satsuma Owari), from the Mediterranean cultivars. Inside this last group, the second discriminant function split up the sabinene chemocultivar (Marisol, Arrufatina Clemenpons and Loretina) from the hybrids group (Fortuna and Nova) and others (Clemenules and Hernandina). The differential compounds of these groups are: $\alpha$-thujene $\alpha$-pinene, sabinene, myrcene, limonene, linalool, $\alpha$-terpineol and germacrene-D. The former group separated a group of recent cultivars with greater concentration of sabinene (Marisol, Arrufatina, Clemenpons and Loretina) from the remainder.

\section{CONCLUSION}

The great importance of Citrus EOs existing in their peel, leaves and flowers, derives from many factors. Because of Citrus are the largest fruit crop in the world, there is a large availability of these oils also as by-product in the wastes of citrus processing. Secondly, the important characteristics and proprieties of Citrus EOs, such as their bactericidal, virucidal, fungicidal, and medicinal properties associated with their fragrance, make them potentially an ideal alternative to the chemical-based antimicrobials for food, agriculture, pharmaceutical and sanitary applications, as well as a precious component of cosmetics and perfumes.

The 'green consumerism', stimulating the use and development of products derived from plants, will take advantages from the use of these kinds of substances. However, many aspects have to be improved regarding their employment, such as a standardisation of the composition for commercial citrus EOs, as well as, deeper studies aimed to better know the active compounds and to clarify the mechanism of their action.

\section{CONFLICT OF INTEREST}

The authors confirm that this article content has no conflicts of interest.

\section{ACKNOWLEDGEMENTS}

Declared none.

\section{REFERENCES}

[1] Figueiredo, C.A.; Barroso, J.G.; Pedro, L.G.; Scheffer, J.J.C. Factors affecting secondary metabolite production in plants: volatile components and essential oils. Flavour Frag. J., 2008, 23, 213-226.

[2] Guenther, E. The Essential Oils; D. Van Nostrand: New York, 1948.

[3] Bakkali,F.; Averbeck,S.; Averbeck, D.; Idaomar, M. Biological effects of essential oils- A review. Food Chem. Toxicol., 2008, 46, 446-473.

[4] Espinosa, S.; Diaz, S.; Brignole, E.A. Optimal design of supercritical fluid processes. Comp. Chem. Engin., 2000, 24(2-7), 1301-1307.

[5] Gao, Y.; Li, B. Extraction of refined oil from citrus peel by supercritical $\mathrm{CO}_{2}$ fluid. J. Univer. Shanghai Sci. Techn., 2005, 27, 207-210.

[6] Lin, Y. H. Study of constitution of pummel peel oil and antibacterial activities of its emulsion for $S$. aureus and E. coli. Master thesis. Taiwan: the Department of Food Science, National Taiwan Ocean University, 2005

Mira, B.; Blasco, M.; Subirats, S. Supercritical $\mathrm{CO}_{2}$ extraction of essential oils from orange peel. J. Supercrit. Fluids, 1996, 9, 238-243.

[8] Angioni, A.; Barra, A.; Coroneo, V.; Dessi, S.; Cabras, P. Chemical composition, seasonal variability, and antifungal activity of Lavandula stoechas $L$. ssp. stoechas essential oils from stem/leaves and flowers. J. Agric. Food Chem., 2006, 54, 4364-4370.

[9] Masotti, V.; Juteau, F.; Bessieère, J.M.; Viano, J. Seasonal and phenological variations of the essential oil from the narrow endemic species Artemisia molinieri and its biological activities. J. Agric. Food Chem., 2003, 51, 71157121.

[10] Carson, C.F.; Riley, T.V.; Non-antibiotic therapies for infectiousdiseases. Commun. Dis. Intell., 2003, 27, 143-146.

[11] Smith, R.L.; Cohen, S.M.; Doull, J.; Feron, V.J.; Goodman, J.I.; Marnett, L.J.; Portoghese, P.S.; Waddell, W.J.; Wagner, B.M.; Hall, R.L., Higley, N.A.; Lucas-Gavin, C.; Adams, T.B. A procedure for the safety evaluation of natural flavor complexes used as ingredients in food: essential oils. Food Chem. Toxicol., 2005, 43, 345-363.

[12] Cosentino, S.; Tuberoso, C.I.G.; Pisano, B.; Satta, M.; Mascia, V.; Arzedi, E.; Palmas, F. In vitro antimicrobial activity and chemical composition of Sardinian Thymus essential oils. Lett. Appl. Microbiol., 1999, 29, 130- 135.

[13] Silva, J.; Abebe, W.; Sousa, S.M.; Duarte, V.G.; Machado, M.I.L.; Matos, F.J.A. Analgesic and anti-inflammatory effects of essential oils of Eucalyptus. J. Ethnopharmacol., 2003, 89, 277-283.

[14] Hajhashemi, V.; Ghannadi, A.; Sharif, B. Anti-inflammatory and analgesic properties of the leaf extracts and essential oil of Lavandula angustifolia Mill. J. Ethnopharmacol., 2003, 89, 67-71.

[15] Perry, N.S.; Bollen, C.; Perry, E.K.; Ballard, C. Salvia for dementia therapy: review of pharmacological activity and pilot tolerability clinical trial. Phar macol. Biochem. Behav., 2003, 75, 651-659.

[16] FAOSTAT database. http://faostat3.fao.org/home/index.html (Accessed January 10, 2013)

[17] González-Molina, E.; Domínguez-Perles ,R.; Moreno, D.A.; GarcíaViguera,C. Natural bioactive compounds of Citrus limon for food and health J. Pharm. Biomed. Anal., 2010, $51,(2), 327-345$.

[18] Schneider, H. In: The citrus industry, Vol. II.; Reuther, W.; Batchelor, L.D.; Webber H.J., Eds.; Berkeley, 1968, pp. 1-85.

[19] Laufenberg, G.; Kunz, B.; Nystroem, M. Transformation of vegetable waste into value added products: (A) the upgrading concept; (B) practical implementations. Biores. Technol., 2003, 87(2), 167-198.

[20] Yamasaki, Y.; Akimitsu, K. In situ localization of gene transcriptions for monoterpene synthesis in irregular parenchymic cells surrounding the secretory cavities in rough lemon (Citrus jambhiri). J. Plant. Physiol., 2007, 164 , 1436-1448.

[21] Germanà, M.A.; De Pasquale, F.; Bazan, E.; Palazzolo, E. Ricerche sugli olii essenziali del flavedo di 44 cloni di Limone. Essenze e Derivati Agrumari, 1987, 3, 421-455.

[22] Germanà, M.A.; Barone, E.; Germanà, M.P.; Palazzolo, E.; Viglianisi G. Indagine sugli oli essenziali e sulla densità delle ghiandole oleifere presenti nel flavedo e nelle foglie di tre cultivar di bergamotto (Citrus bergamia Risso). Italus Hortus, 1995, 2(4), 42-48.

[23] De Pasquale, R.; Rapisarda A.; Germanà, M.A.; De Pasquale, F. Ricerche su alcuni aspetti morfologici del flavedo di differenti cultivar di limone (Citrus limon L. Burm. f.). Eur. Rev. Med. Pharmacol. Sci., 1990, 12, 437-451.

[24] Dugo, P.; Mondello, L.; Dugo, L.; Stancanelli, R.; Dugo, G. LC-MS for the identification of oxygen heterocyclic compounds in citrus essential oils. $J$. Pharmacol. Biomed. Anal., 2000, 24(1), 147-154.

[25] Borgmann, S.; Niklas, D. M.; Klare, I.; Zabel, L. T.; Buchenau, P.; Autenrieth, I. B.; Two episodes of vancomycin-resistant Enterococcus faecium outbreaks caused by two genetically different clones in a newborn intensive care unit. Int. J. Hyg. Envir. Heal., 2004, 207, 386-389.

[26] Smith, D. C.; Forland, S.; Bachanos, E.; Matejka, M.; Barrett, V. Qualitative analysis of citrus fruits extracts by GC/MS: An undergraduate experiment. Chemical Educator, 2001, 6, 28-31.

[27] Flamini, G.; Tebano, M.; Cioni, P. Volatiles emission patterns of differen plant organs and pollen of Citrus limon. Anal. Chim. Acta, 2007, 589, 120124.

[28] Svoboda, K.; Greenaway, R. I. Lemon scented plants. Int. J. Aromather. 2003, 13(1), 23-32

[29] Moufida, S.; Marzouk, B. Biochemical characterization of blood orange sweet orange, lemon, bergamot and bitter orange. Phytochem., 2003, 62(8), 1283-1289.

[30] Crescimanno, F.G.; De Pasquale, F.; Germanà, M.A.; Bazan, E.; Palazzolo, E. Influence of the harvesting period on the yield of essential oil from the peel of four Lemon cultivars (C. limon (L.) Burm. f.). Proceedings of the $6^{\text {th }}$ Citrus Congress: Tel Aviv, Israel, 1988c; pp. 589-595.

[31] Jeannot, V.; Chahboun, J.; Russell, D.; Baret, P. Quantification and determination of chemical composition of the essential oil extracted from natural orange blossom water (Citrus aurantium L. ssp. aurantium). Int. J. Aromather. 2005, 15(2), 94-97

[32] Benvenuti, F.; Gironi, F.; Lamberti, L. Supercritical deterpenation of lemon essential oil, experimental data and simulation of the semicontinuous extraction process. J. Supercrit. Fluids, 2001, 20(1), 29-44

[33] Crescimanno, F.G.; De Pasquale, F.; Germanà, M.A; Bazan, E.; Palazzolo, E. Research on Neroli oils in 15 sour orange (C. aurantium L.) clones. Proceedings of the $2^{\text {nd }}$ Mediterranean Tree Crops Meeting: Chania, Grecia, 1988, pp. 285-293.

[34] Pennisi, L. In: Trattato di agrumicoltura. Edagricole; Bologna, 1985.

[35] Melendreras, F.A.; Laencina, J.; Flores, J.; Guzman, G. Aceites esenciales en flores de variedades de limonero (Citrus limon L. Burm. F.) Agrochim., 1986, 30(4-5), 276-288.

[36] Raguso, R.; Pichesky, E. A day in the life of a linalool molecule: Chemica communication in a plant-pollinator system. Part 1: Linalool biosynthesis in flowering plants. Plant Species Biol., 1999, 14(2), 95-120.

[37] Germanà, M.A.; Germanà, M.P.; Palazzolo E. Studi sugli oli essenziali dei fiori di tre cultivar di Citrus bergamia Risso. Essenze e Derivati Agrumari, 1993, 63(3), 243-257.

[38] Germanà, M.A.; De Pasquale, F.; Bazan, E.; Palazzolo, E. Indagine sugli oli essenziali contenuti nei fiori, nelle foglie e nei germogli di 5 specie di Citrus. Essenze e Derivati Agrumari, 1990a, 3, 297-296. 
[39] Germanà, M.A.; De Pasquale, F.; Bazan, E.; Palazzolo, E. Ricerche sugli oli essenziali delle differenti parti del fiore di diversi cloni di Citrus aurantium L. Essenze e Derivati Agrumari, 1990b, 3, 287-296.

[40] Crescimanno, F.G.; De Pasquale, F.; Germanà, M.A.; Bazan, E.; Palazzolo, E. Annual variation of essential oils in the leaves of four lemon (C. limon $L$. Burm. f.) cultivars. Proceedings of the $6^{\text {th }}$ Citrus Congress: Tel Aviv, Israel, 1988; pp. 583-588.

[41] Settanni, L.; Palazzolo, E.; Guarrasi, V.; Aleo, A.; Mammina, C.; Moschetti, G.; Germanà, M.A. Inhibition of foodborne pathogen bacteria by essential oils extracted from citrus fruits cultivated in Sicily. Food Control, 2012, 26, 326-330.

[42] Velázquez-Nuñez, M.J.; Avila-Sosa, R.; Palou, E.; López-Malo, A. Antifungal activity of orange (Citrus sinensis var. Valencia) peel essential oil applied by direct addition or vapor contact. Food Control, 2013, 31, 1-4.

[43] Bajpai, V. K.; Baek, K.-H.; Kang, S. C. Control of Salmonella in foods by using essential oils: a review. Food Res. Int., 2012, 45, 722-734.

[44] Tunc, S.; Duman, O. Preparation of active antimicrobial methyl cellulose/carvacrol/montmorillonite nanocomposite films and investigation of carvacrol release. LWT-Food Sci. Techn., 2011, 44, 465-472.

[45] Burt, S. Essential oils: their antibacterial properties and potential applications in foods. A review. Int. J. Food Microbiol., 2004, 94, 223- 253.

[46] Chida, M.; Tyamashita, K.; Izumyia, Y.; Wantanabe, K.; Tamura, H.Aroma impact compounds in three Citrus oils: crossmatching test and correspondence analysis approach. J. Food Sci., 2006, 71(1), 56-58.

[47] Arce, A.; Pobudkowska, A.; Rodriguez, O.; Soto, A. Citrus essential oil terpenless by extraction using 1-ethyl-3-methylimidazolium ethylsulphate ionic liquid: effect of the temperature. Chem. Eng. J., 2007, 133, 213-218.

[48] Dias, M.V.; de Medeiros, H.S.; de Fátima Ferreira Soares, N.; de Melo, N.R.; Borges, S.V.; de Deus Souza Carneiro, J.; de Assis Kluge Pereira, J.M.T. Development of low-density polyethylene films with lemon aroma. LWT Food Sci. Techn., 2013, 50 167-171

[49] Kim, J.; Marshall, M.R.; Wei, C.-I. Antibacterial activity of some essential oil components against five foodborne pathogens. J. Agric. Food Chem., $\mathbf{1 9 9 5}, 43,2839-2845$

[50] Mattick, K.; Durhan, K.; Xendris, M.; Slader, J.; Griffth, C.; Sen, T. The microbiological quality of washing-up water and environment in domestic and commercial kitchens. J. Appl. Microbiol., 2003, 94(5), 842-848.

[51] Saouter, E.; Pittinger, C.; Feijtel, T. Aquatic environmental impact of detergents: from simple to more sophisticated models. Ecotoxicol. Environ. Saf., 2001, 50(2)153-159.

[52] Sonnenschein, C.; Soto, A.M. In: The society of cells: Control of cell proliferation and cancer. Bios Scientific, Oxford, 1999

[53] Fisher, K.; Phillips C. Potential antimicrobial uses of essential oils in food: is citrus the answer? Trends Food. Sci. Tech., 2008, 19, 156-164.

[54] Caccioni, D. R. L.; Guizzardi, M.; Biondi, D. M ; Renda, A; Ruberto, G. Relationship between volatile components of citrus fruit essential oils and antimicrobial action on Penicillium digitatum and Penicillium italicum. Int. J. Food Microbiol., 1998, 43(1/2), 73-79.

[55] Lin, C.M.; Sheu, S.R.; Hsu, S.C.; Tsai, Y.H. Determination of bactericidal efficacy of essential oil extracted from orange peel on the food contact surfaces. Food Control, 2010, 21, 1710-1715.

[56] Tyagi, A.K.; Malik, A..Antimicrobial potential and chemical composition of Mentha piperita oil in liquid and vapour phaseagainst food spoiling microorganism. Food Control, 2011, 22, 1707-1714.

[57] Crowell, P.L. Prevention and therapy of cancer by dietary monoterpenes. $J$. Nutr., 1999, 129, 775-778.

[58] Lewis, D.A.; Hanson P.J. Anti-ulcer drugs of plant origin, Progr. Med. Chem., 1991, 28, 201-231.

[59] Sanguinetti, M.; Posteraro, B.; Fiori, B. Mechanisms of azole resistance in clinical isolates of Candida glabrata collected during a hospital survey of antifungal resistance. Antimicrob. Agents Chemother., 2005, 49, 668-679.

[60] Moraes, T.M.; Kushima, H.; Moleiro, F.C.; Santos, R.C.; Machado Rocha, L.R.; Marques, M.O.; Vilegas, W.; Hiruma-Lima, C.A. Effects of limonene and essential oil from Citrus aurantium on gastric mucosa: Role of prostaglandins and gastric mucus secretion. Chem. Biol. Interact., 2009, 180, 499505 .

[61] Wilkins Jr, J. Method for treating gastrointestinal disorder, US Patent 642,$045 ; 2002$.

[62] Odeh, F.; Abdulkader, R.A.; Alnori, S.M.; Chaty, E. The cytotoxic effect of essential oils Citrus aurantium peels on human colorectal carcinoma cell line (LIM1863). J. Microbiol. Biotech. Food Sci., 2012, 1(6) 1476-1487.

[63] Komori, T.; Fujiwara, R.; Tanida, M.; Nomura, J. Potential antidepressant effects of lemon odor in rats. Eur. Neuropsychopharmacol., 1995, 5, 477-80.

[64] Knasko, S.C. Ambient odor's effect on creativity mood and perceived health. Chem. Sense, 1992, 17(1), 27-35.

[65] Manley, C.H. Psychological effect of odor. Crit. Rev. Food Sci. Nutr., 1999, $333,57-62$.
[66] Tsuchiya, T.; Tanida, M.; Uenoyama, S.; Nakayama ,Y.; Ozawa T. Effects of olfactory stimulation on the sleep time induced by pentobarbital administration in mice. Brain. Res. Bull., 1991, 26, 397-401.

[67] Sanguinetti M.; Posteraro, B.; Romano, L.; Battaglia, F.; Lopizzo, T.; De Carolis, E.; Fadda, G. In vitro activity of Citrus bergamia (bergamot) oil against clinical isolates of dermatophytes. J. Antimicrob. Chemother., 2007, 59, 305-308.

[68] Maruzzella, J. C.; Henry, P. A. The in vitro antimicrobial activity of essential oils and oil combinations. J. Amer. Pharm. Ass. Sci., 1958, 47, 294-296.

[69] Maruzzella, J. C.; Henry, P. A. The antimicrobial activity of perfume oils. $J$. Amer. Pharm. Ass. Sci., 1958, 47, 471-476.

[70] Maruzzella, J. C.; Lichtenstein, M. B. The in vitro antimicrobial activity of oils. J. Amer. Pharm. Ass. Sci. 1956, 45, 378-381.

[71] Maruzzella, J. C.; Scrandis D. A. Scrandis, J. B; Grabon, G. Action of odoriferous organic chemicals and essential oils on wood-destroying fungi. Plant Dis., 1960, 44, 789-792.

[72] Maruzzella, J. C.;. Liguori., L. The in vitro antifungal activity of essential oils. J. Amer. Pharm. Ass. Sci., 1958, 47, 250-254

[73] Maruzzella, J.C.; Balter, J. The action of essential oils on phytopathogenic fungi. Plant Dis. Rep., 1959, 43, 1143-1147.

[74] Tisserand, R.; Balocs, T. Essential oil safety. A Guide Health Care Professional; Edinburgh, 1995.

[75] Zaynoun, S.T.; Johnson, B.E.; Frain-Bell, W. A study of oil Bergamot and its importance as phototoxic agent. Contact Dermatitis, 1977, 3(5), 225-239.

[76] Naganuma, M.; Hirose, S.; Nakayama, Y.; Nakaijma, K.; Someya, T. A study of photoxicity of lemon oil. Arch. Dermatol. Res., 1985, 278(1), 31-36. SCCNFP, 2001. Opinion of the Scientific Committee on Cosmetic Products and Non-Food Products Intended for Consumers concerning An initial list of perfumery materials which must not form part of cosmetic products except subject to the restrictions and conditions laid down. SCCNFP/0392/00. <http://ec.europa.eu/health/ph_risk/committees/sccp/documents/out150_en.p df> (Accessed, January, 2013);

[78] Kejlová, K.; Jírová, D.; Bendová, H.; Gajdoš, P.; Kolárǒvá, H. Phototoxicity of essential oils intended for cosmetic use. Toxicol. Vitro, 2010, 24, 2084 2089.

[79] Xu, Y. Contextual tonal variations in Mandarin. J. Phonetics, 1997, 25, 6183.

[80] Sawamura, M.; Son, U.S.; Choi, H.S.; Kim, M.L.; Phin, N.T.L.; Fears, M. Composition changes in commercial lemon essential oil for aromatherapy. Int. J. Aromather., 2004, 4, 27-33.

[81] Matsuura, R.; Ukeda, H.; Sawamura, M. Tyrosinase inhibitory activity of citrus essential oils J. Agric. Food Chem., 2006, 54, 2309-2313.

[82] Carson, C.F., Hammer, K.A., In: Lipids and essential oils as antimicrobial agents, John Wiley \& Sons: United Kingdom, 2011, pp. 203-238.

[83] Lawless, J. The encyclopedia of essential oils. Thorsons, London, 2002.

[84] Buchbauer, G.; Jager, W.; Jirovetz, L.; Imberger J. Dietrich H. Therapeutic properties of essential oils and fragrances. Acs. Sym. Ser., 1993, 12, 159-165.

[85] Lahlou, M. Methods to study the phytochemistry and bioactivity of essential oils. Phytother. Res., 2004, 18, 435-448

[86] Thomas, D. Aromatherapy: mythical, magical, or medicinal? Holistic Nursing Practice, 2002, 16(5), 8-17.

[87] Carvalho-Freitas, M.I.R. Costa, M. Anxiolytic and sedative effects of extracts and essential oil from Citrus aurantium L. Biol. Pharm. Bull., 2002, 25, 1629- 1633 .

[88] de Moraes Pultrini, A.; Almeida Galindo, L.; Costa, M. Effects of the essential oil from Citrus aurantium L. in experimental anxiety models in mice. Life Sci., 2006, 78, 1720-1725.

[89] Faturi, C.B.; Leite, J.R.; Alves, P.B.; Canton, A.C.; Teixeira-Silva, F. Anxiolytic-like effect of sweet orange aroma in Wistar rats. Prog. Neuropsychopharmacol. Biol. Psychiatry, 2010, 34(4), 605-609.

[90] Lima, N.G.; De Sousa, D.P.; Pimenta, F.C.; Alves, M.F.; De Souza, F.S.; Macedo, R.O.; Cardoso, R.B.; de Morais, L.C.; Melo Diniz Mde, F.; de Almeida, R.N. Anxiolytic-like activity and GC-MS analysis of (R)-(+)limonene fragrance, a natural compound found in foods and plants. Pharmacol. Biochem. Behav., 2013, 103(3), 450-454.

[91] Vasudeva, N.; Sharma, T. Chemical Composition and Antimicrobial Activity of Essential Oil of Citrus limettioides Tanaka. J. Pharmacol. Techn. Drug Res., 2012, http://www.hoajonline.com/journals/pdf/2050-120X-1-2.pdf

[92] Michaelakis, A.; Papachristos, D., Kimbaris, A., Koliopoulos, G., Giatropoulos, A., Polissiou, M.G. Citrus essential oils and four enantiomeric pinenes against Culex pipiens (Diptera: Culicidae). Parasitol. Res., 2009, 105(3), 769-773.

[93] Kumar, P.; Mishra, S.; Malik, A.; Satya, S. Insecticidal evaluation of essential oils of Citrus sinensis L. (Myrtales: Myrtaceae) against housefly, Musca domestica L. (Diptera: Muscidae). Parasitol. Res., 2012, 110, 1929-1936.

[94] Blanquer, A.; Boira, H.; Soler, V.; Perez, I. Variability of the essential oil of Thymus piperella. Phytochem., 2011, 47, (7), 1271-1276.

[95] Lebot, V.; Levesque, J. Genetic control of kavalactone chemotypes in Piper methysticum cultivars. Phytochem. 1996, 4(2), 397-403. 